\title{
Correction to: The current status of survivorship care provision at the state level: a Wisconsin-based assessment
}

\author{
Alexandria L. Cull Weatherer ${ }^{1}$ [ $\cdot$ John K. Krebsbach ${ }^{1} \cdot$ Amye J. Tevaarwerk $^{1,2} \cdot$ Sarah C. Kerch $^{1} \cdot$ Noelle K. LoConte $^{1,2}$ \\ ๑) Springer Science+Business Media, LLC, part of Springer Nature 2022
}

\section{Corrections to: J Cancer Surviv} https://doi.org/10.1007/s11764-021-01117-4

There are two file upload errors in the supplement section of this article. Corrected files can be found below.

Supplement one/Supplementary file one should be PatientCentered Outcomes Research Institute (PCORI) project (IH12-11-5255) Evaluating Cancer Survivorship Care Model

Patient-Centered Survivorship Care Index Implementation Tools-Final Adaptable

Supplement two/Supplementary file two should be 2020 Wisconsin Survivorship Care Survey

2020 Wisconsin Survivorship Care Survey

The Original article has been revised.

Publisher's note Springer Nature remains neutral with regard to jurisdictional claims in published maps and institutional affiliations.

The online version of the original article can be found at https:// doi.org/10.1007/s11764-021-01117-4

Alexandria L. Cull Weatherer acull@wisc.edu

1 University of Wisconsin Carbone Cancer Center, $610 \mathrm{~N}$ Walnut St. Room 370 WARF, Madison, WI 53726, USA

2 Department of Medicine, School of Medicine and Public Health, University of Wisconsin, Madison, WI, USA 